\title{
Metachronous extranodal natural killer/T-cell lymphoma of nasal type and primary testicular lymphoma
}

\author{
Young-In Maeng, Sun-Jae Lee \\ Department of Pathology, Daegu Catholic University School of Medicine, Daegu, Korea
}

Received: July 24, 2020

Revised: August 18, 2020

Accepted: August 18, 2020

Corresponding author:

Sun-Jae Lee, MD, PhD

Department of Pathology, Daegu

Catholic University School of

Medicine, 33 Duryugongwon-ro

17-gil, Nam-gu, Daegu 42472,

Korea

Tel: +82-53-650-4629

Fax: +82-53-650-3050

E-mail: pathosjlee@cu.ac.kr
We report a rare case of metachronous lymphoma with two distinct cell lineages in a 75-yearold man. The patient complained about having nasal obstruction for 2 years and extranodal natural killer (NK)/T-cell lymphoma of the nasal type was diagnosed from a biopsy. The immunohistochemical staining for CD56 and in situ hybridization for Epstein-Barr virus (EBV)-encoded small RNA (EBER-ISH) were positive and the tumor cells were negative for CD20. After 13 months of concurrent chemoradiotherapy, the patient presented with swelling of the left testis. Positron emission tomography scan detected an abnormal uptake in the testis. A diffuse large B-cell lymphoma, not otherwise specified, was diagnosed from subsequent radical orchiectomy. The immunohistochemical staining revealed to be positive for CD20, BCL2, BCL6, and MYC and negative for CD10 and EBER-ISH.

Keywords: Diffuse large B-cell lymphoma; Extranodal NK/T-cell lymphoma; Lymphoma; Nasal type; Testicular cancer

\section{Introduction}

A metachronous lymphoma occurs when the second primary lymphoma is diagnosed more than 6 months after the diagnosis of the primary lymphoma. In this article, we report a metachronous extranodal natural killer (NK)/T-cell lymphoma, nasal type, and a primary testicular lymphoma.

Extranodal NK/T-cell lymphoma, nasal type, is an extranodal lymphoma of the NK-cell or T-cell lineage, which is prevalent in Asians with a strong association with Epstein-Barr virus (EBV). On the other hand, primary testicular lymphoma is a rare form of extranodal non-Hodgkin lymphoma (NHL), accounting for $1 \%$ to $2 \%$ of NHL cases [1]. Most cases are diffuse large B-cell lymphoma (DLBCL) with extranodal tropism and frequent relapses. To the best of our knowledge, there is no previous report of metachronous lymphoma, including extranodal NK/T-cell lymphoma, nasal type, and primary testicular DLBCL.

\section{Case}

The patient presented with symptoms of nasal obstruction for 2 years with a previous medical history of operation for rectal cancer. The initial laboratory test results were white blood cells count, 8,800/ $\mu \mathrm{L}$; hemoglobin, $10.2 \mathrm{~g} / \mathrm{dL}$; hematocrit, $31.2 \%$; and platelet, $180,000 / \mu \mathrm{L}$. The initial computed tomography $(\mathrm{CT})$ results showed both maxillary and ethmoidal sinusitis. The patient underwent an endoscopic biopsy for the necrosis area. Microscopic findings showed necrosis of the nasal mucosa with a diffuse infiltration of small-to-medium-sized lymphoid cells. The immunophenotype of the tumor cells was identified as CD56, CD30, cytoplasmic $\mathrm{CD} 3$ positive, and the in situ hybridization for $\mathrm{EBV}$-encoded small RNA (EBER-ISH) was positive, but they were CD20 negative (Fig. 1). The T-cell receptor (TCR)-gamma gene rearrangement test detected no clonality. The cellularity of the bone marrow was $40 \%$, presenting a normocellular marrow without any tumor cell. The EBV-DNA was elevated to 4.21 copies/ $\mu \mathrm{L}$. The positron

Copyright (C) 2021 Yeungnam University College of Medicine

This is an Open Access article distributed under the terms of the Creative Commons Attribution Non-Commercial License (http://creativecommons.org/licenses/by-nc/4.0/) which permits unrestricted non-commercial use, distribution, and reproduction in any medium, provided the original work is properly cited. 
emission tomography (PET) scan revealed no evidence of abnormal hypermetabolic lesions other than that in the nasal cavity. Taken together, a diagnosis of extranodal NK/T-cell lymphoma of the nasal type was made. The patient received concurrent cisplatin and radiotherapy, followed by two cycles of VIPD (etoposide, ifosfamide, cisplatin, and dexamethasone).

Thirteen months after the diagnosis of extranodal NK/T-cell lymphoma of the nasal type, the patient presented with swelling of his left testis and a prominent paraaortic lymph node at the level of the renal hilum, during the follow-up abdominal CT. The regularly performed otolaryngologic examination and endoscopic findings showed no abnormality in the nasal cavity. The follow-up PET scan revealed a hypermetabolic mass in the left testis and a paraaortic lymph node, but there was no abnormal uptake in the nasal cavity and no significantly enlarged lymph node was identified in the neck. The patient underwent left radical orchiectomy. The microscopic findings of the testis showed a total architectural effacement based on the diffuse proliferation of large lymphoid cells. Immunohistochemical staining results of tumor cells showed that these were positive for CD20, MYC, BCL2, and BCL6, but negative for CD3, CD10, CD30, ALK, and EBER-ISH (Fig. 2). Ki-
67 was positive in $90 \%$ of tumor cells. The serum EBV titer was lower than the detection limit. Clonality was also detected using a clonal immunoglobulin heavy chain gene rearrangement test, the BIOMED-2 clonality assay (InVivoScribe Technologies, San Diego, CA, USA). Therefore, the patient was diagnosed with DLB$\mathrm{CL}$, not otherwise specified (NOS). The patient received seven cycles of chemotherapy using R-CHOP (rituximab, cyclophosphamide, doxorubicin, vincristine, and prednisone), combined with intrathecal methotrexate.

\section{Discussion}

Metachronous lymphoma is defined as the case in which the second primary lymphoma is diagnosed more than 6 months after the diagnosis of the primary lymphoma. In the present case, two types of lymphoma were diagnosed with an interval of 13 months. To the best of our knowledge, metachronous lymphoma, including extranodal NK/T-cell lymphoma of the nasal type, and primary testicular DLBCL have not been reported yet.

Extranodal NK/T-cell lymphoma of the nasal type, a highly aggressive tumor, is prevalent in Asia. It has a strong association with
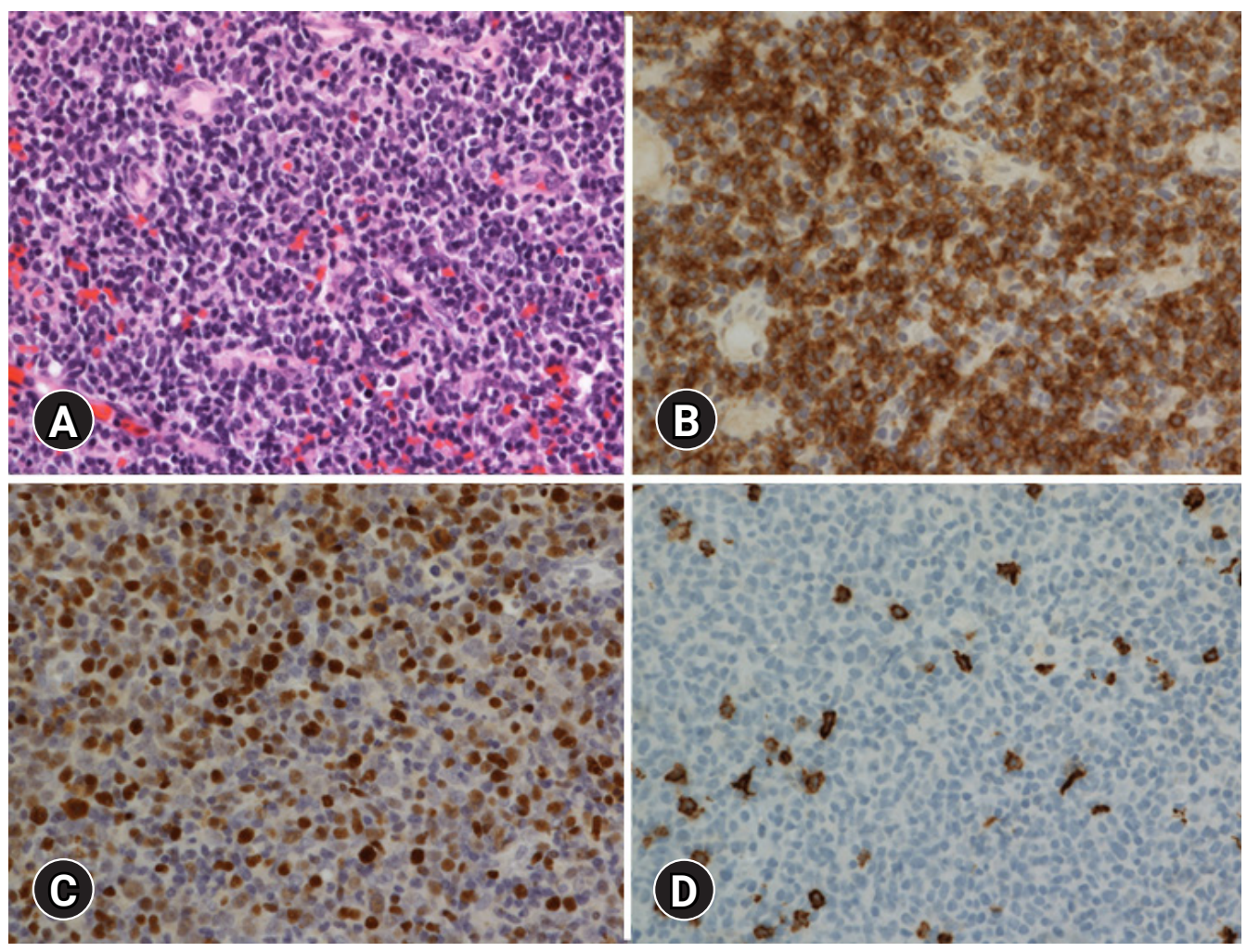

Fig. 1. Histologic and immunohistochemical findings. (A) Diffuse infiltration of small-to-medium-sized lymphoid cells is observed (hematoxylin and eosin stain, $\times 400$ ). (B) Tumor cells are positive for CD56 (immunohistochemical stain, $\times 400$ ). (C) Tumor cells are positive for Epstein-Barr virus (EBV) (in situ hybridization for EBV-encoded small RNA, x400). (D) Tumor cells are negative for CD20 (immunohistochemical stain, $\times 400$ ). 

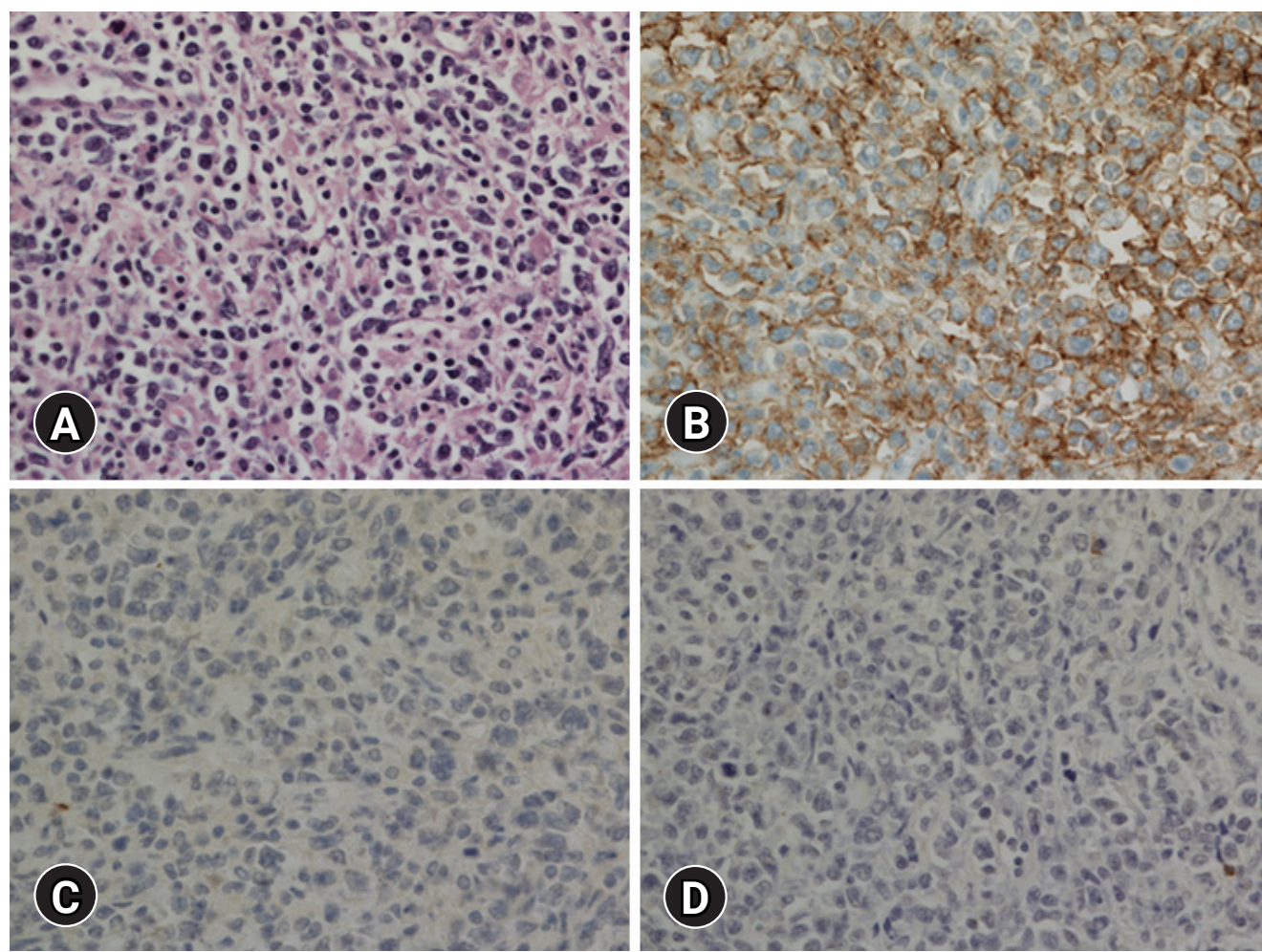

Fig. 2. Histologic and immunohistochemical findings of the left testis. (A) Microscopic findings show a diffuse proliferation of large lymphoid cells (hematoxylin and eosin stain, x400). (B) Tumor cells are positive for CD20 (immunohistochemical stain, x400). (C) Tumor cells are negative for CD56 (immunohistochemical stain, x400). (D) Tumor cells are negative for Epstein-Barr virus (EBV) (in situ hybridization for Epstein-Barr virus-encoded small RNA, x400).

EBV, suggesting that EBV might play a pathogenic role in this type of lymphoma [2]. Immunohistochemical phenotypes and histological findings of EBV infections are compatible with those of extranodal NK/T-cell lymphoma of the nasal type. However, rare cases of CD56 or EBV positive peripheral T-cell lymphoma, NOS, have been described previously [3]. In the present case, a TCR-gamma gene rearrangement test confirmed the diagnosis of extranodal NK/T-cell lymphoma of the nasal type. The prognosis of this kind of lymphoma is poor, although a longer survival is expected with intensive chemotherapy and radiotherapy [2]. In the present case, the patient received concurrent cisplatin and radiotherapy, followed by two cycles of VIPD.

DLBCL, NOS is a neoplasm with a large B lymphoid cell with unknown etiology. DLBCL, NOS usually arises de novo. Secondary DLBCL is transformed from other less aggressive lymphomas. On the other hand, primary testicular lymphoma can arise from an immune-privileged site, traditionally described as an "immune sanctuary" site [4]. Although primary testicular lymphoma shares its biology with primary DLBCL of the central nervous system (CNS), it is currently classified as DLBCL, NOS. The majority of cases are DLBCL with a non-germinal center B-cell (GCB) sub- type $[5,6]$. Immunohistochemical staining shows that both BCL2 and MYC proteins are expressed as a double expressor phenotype in $80 \%$ of cases [7]. The distinction between primary and secondary DLBCL, NOS in immune-privileged sites is essential. An evaluation of the systemic disease is needed for an unusual GCB subtype [6]. Immunophenotypes of the present case coincided with a typical primary testicular lymphoma. The characteristics of primary testicular lymphoma include a continuous pattern of relapse and an increased risk of CNS involvement [8]. The treatment and prognostic factors of primary testicular lymphoma remain controversial. However, the $\mathrm{CHOP}$ regimen is the mainstay of therapy with rituximab. The patient underwent radical orchiectomy and seven cycles of R-CHOP, accompanied by intrathecal methotrexate.

In conclusion, we present a rare case of primary testicular lymphoma of DLBCL, NOS, occurring 13 months after the treatment of extranodal NK/T-cell lymphoma of the nasal type. Results of microscopic findings, immunohistochemical staining, and clonality test revealed that the tumors of the patient were histologically different, originating from two different clones. The etiologies of these two metachronous lymphomas remain unknown. The standard therapy and characteristics of the tumor should be followed in 
further study.

\section{Notes}

\section{Ethical statements}

This study was approved by the Institutional Review Board (IRB) of Daegu Catholic University Medical Center (IRB No: CR 20136-L) and written informed consent from patient was waived by IRB.

\section{Conflicts of interest}

No potential conflict of interest relevant to this article was reported.

\section{Author contributions}

Conceptualization and Formal analysis: MYI, LSJ; Data curation and Investigation: MYI; Writing - original draft: MYI; Writing - review \& editing: LSJ.

\section{ORCID}

Young-In Maeng, https://orcid.org/0000-0002-9165-9542

Sun-Jae Lee, https://orcid.org/0000-0002-8552-6049

\section{References}

1. Møller MB, d'Amore F, Christensen BE; Danish Lymphoma Study Group. Testicular lymphoma: a population-based study of incidence, clinicopathological correlations and prognosis. Eur J Cancer 1994;30:1760-4.

2. Chan JK, Quintanilla-Martinez L, Ferry JA. Extrannodal NK/
T-cell lymphoma, nasal type. In: Swerdlow SH, Campo E, Harris NL, Jaffe ES, Pileri SA, Stein H, et al., editors. WHO classification of tumours of haematopoietic and lymphoid tissues. 4th ed. Lyon: IARC Press; 2017.p. 368-71.

3. Pileri SA, Weisenburger DD, Sng I, Nakamura S, Muller-Hermelink HK, Chan WC, et al. Peripheral T-cell lymphoma, NOS. In: Swerdlow SH, Campo E, Harris NL, Jaffe ES, Pileri $\mathrm{SA}$, Stein $\mathrm{H}$, et al., editors. WHO classification of tumours of haematopoietic and lymphoid tissues. 4 th ed. Lyon: IARC Press; 2017.p. 403-6.

4. King RL, Goodlad JR, Calaminici M, Dotlic S, Montes-Moreno S, Oschlies I, et al. Lymphomas arising in immune-privileged sites: insights into biology, diagnosis, and pathogenesis. Virchows Arch 2020;476:647-65.

5. Booman M, Douwes J, Glas AM, de Jong D, Schuuring E, Kluin PM. Primary testicular diffuse large B-cell lymphomas have activated B-cell-like subtype characteristics. J Pathol 2006;210: $163-71$.

6. Cheah CY, Wirth A, Seymour JF. Primary testicular lymphoma. Blood 2014;123:486-93.

7. Brunn A, Nagel I, Montesinos-Rongen M, Klapper W, Vater I, Paulus W, et al. Frequent triple-hit expression of MYC, BCL2, and BCL6 in primary lymphoma of the central nervous system and absence of a favorable MYC(low)BCL2 (low) subgroup may underlie the inferior prognosis as compared to systemic diffuse large B cell lymphomas. Acta Neuropathol 2013; 126:603-5.

8. Fonseca R, Habermann TM, Colgan JP, O'Neill BP, White WL, Witzig TE, et al. Testicular lymphoma is associated with a high incidence of extranodal recurrence. Cancer 2000;88:154-61. 